form of a letter, the size of the lamp glass does not bear the same relation to the distance at which the lamp is visible, as in the case of form vision.

The same men were tested with the Edridge-Green lantern immediately after the outdoor test, and it was shown that each man with vision $6 / 18,6 / 18$, both $6 / 12$, was quite accurate with dull red lights. This is our everyday experience, and we hold that if the form vision is not reduced below $6 / 12$ with both eyes open, the colour perception is safe-always excepting toxic amblyopia. A shortened red end to the spectrum should not be diagnosed unless the vision is improved to $6 / 6$, or unless a large (half inch) aperture be used.

Conclusions :- -

(1.) Under ideal conditions a man with vision R. 6/18, L. 6/18, both $6 / 12$, can, with both eyes open, read signals accurately at 1,500 yards.

(2.) Provided that the vision with both eyes open is not below $6 / 12$, colour perception is not dangerously lowered.

NotE.-The complete records of these experiments are in the files of the Railway Department referred to.

\title{
REMOVAL OF FILARIA FROM UNDER THE CONJUNCTIVA
}

r.Y

\section{E. Charles}

GUJRANWALA

BAGga S/O HiRA, aged 45, resident of Sialkot District, near Jammu State Territory, had, some eight months ago, sudden severe pain in his right eye, and soon after he felt a little swelling on the inner and downward side of his eyeball. The pain of a neuralgic type stopped when cold, but increased in the daytime.

Present condition.-Fairly large swelling on the inner and downward side of the right eye beneath the ocular conjunctiva, redness, watering, pupil dilated, patient in great pain, vision not affected.

Operation.-Under cocain, two days after admission, a small incision with a Graefe's knife was made in the swelling, and a loop of the living worm began to come out of the opening. Just when the head of the thing was being pulled at the patient complained of severe pain, the pull was loosened and the worm began to crawl in again; when just a little of the worm had gone back a sudden pull 
brought out the whole of the worm. Recovery was uneventful, the patient was discharged cured about a week after. I should be glad to hear through your paper if anyone else has ever had any worm like that removed from an eye, and something more about the mode of its location in the eye.

\section{Note on Mr. Charles's Specimen by Major Sewell}

The specimen by Mr. Charles is unfortunately so contracted and shrunken, owing to its having been preserved in spirit, that it is impossible to arrive at any definite conclusion with regard to it. It appears to be a female Filaria. The worm measures $33 \mathrm{~mm}$. in length by $2 \mathrm{~mm}$. in width throughout the greater part of its length, but in life it must have been somewhat larger than this. The body of the worm is flattened from side to side and the colour is pale yellowish white. The cuticle is transversely striated, and throughout the whole length of the body longitudinal striae can be seen in the body wall. The anterior end is club-shaped and devoid of papillae and the mouth is situated terminally. At the posterior end there is a pair of rounded folds or prominences situated close together ventrally just in front of the extreme tip, which is somewhat truncated. In all probability the worm is an example of Filaria (?) conjunctivae Addario. There appears to be a considerable confusion in the literature regarding this worm and in consequence the classification must be regarded as doubtful. Similar, if not identical, worms have been from time to time recorded from a similar situation. Dubini was the first to record a case from the eye of a man in Italy, and Addario obtained a specimen from a cyst in the ocular conjunctiva. Another example was found by Alessandrini, in 1906. . Braun gives Filaria inermis Grassi, F. apabillocephala CondorelliFrancaviglia and $F$. peritonei hominis Babes, as synonyms. In the case of this latter example the worm was found in the gastro-splenic omentum. Possibly the worm described under the name Agamofilaria palpebralis Pace in 1867, which was taken from a cyst in the eyelid of a patient is still a further example. Very little is known about this group; the term Agamofilaria, under which heading several different species are described, is not a generic name but "a group name for immature Filaria, the development of which does not admit of generic determination" (Fantham. Theobald). 